\title{
Basal cell nevus syndrome (Gorlin-Goltz syndrome): genetic predisposition, clinical picture and treatment
}

\author{
Henryk Witmanowski ${ }^{1,2}$, Paweł Szychta ${ }^{1,3}$, Katarzyna Błochowiak $^{4}$, Arkadiusz Jundziłł ${ }^{3}$, Rafał Czajkowski ${ }^{5}$ \\ ${ }^{1}$ Department of Plastic, Reconstructive and Aesthetic Surgery, Medical College in Bydgoszcz, Nicolaus Copernicus University in Torun, \\ Poland \\ ${ }^{2}$ Department of Physiology, Poznan University of Medical Sciences, Poznan, Poland \\ ${ }^{3}$ Department of Surgical Oncology and Breast Diseases, Institute of Polish Mother's, Memorial Hospital Research Institute, Lodz, \\ Poland \\ ${ }^{4}$ Department of the Oral Surgery, Poznan University of Medical Sciences, Poznan, Poland \\ ${ }^{5}$ Department of Dermatology, Sexually Transmitted Diseases and Immunodermatology, Medical College in Bydgoszcz, \\ Nicolaus Copernicus University in Torun, Poland
}

Adv Dermatol Allergol 2017; XXXIV (4): 381-387 DOI: https://doi.org/10.5114/ada.2017.69323

Gorlin-Goltz syndrome (Online Mendelian Inheritance in Man, MIM, 109400), also called nevoid basal cell carcinoma syndrome (BCCS) or basal cell nevus syndrome (BCNS), is a multisystemic autosomal dominant disorder with a high penetrance and variable expressiveness [1]. The classical triad is composed of multiple basal cell carcinomas, keratocystic odontogenic tumors and bifid ribs. The disease is variably associated with other neurological, ophthalmic, endocrine and genital manifestations, with onset during the first, second and third decades of life [2]. The estimated prevalence is $1 / 60,000$ and varies from $1 / 30827$ to $1 / 256000[3,4]$. It affects males and females equally and arises in all ethnic groups, but most of reported cases are in whites [5].

The genodermatosis is caused in most cases by heterozygous mutations in tumor suppressor gene PTCH, located on chromosome 9q22.3 [6]. Molecular germline mutations in BCNS include frameshift, nonsense, missense and splicing mutations, exonic, multi-exonic or rearrangements [7]. The PTCH1 gene encodes a transmembrane glycoprotein that acts as the antagonist receptor for the sonic hedgehog ligand in the hedgehog and smoothened (SMO) signaling pathways [8]. Hedgehog and SMO signaling pathways regulate cell growth and development and thus their disruption results in developmental anomalies and tumors [9]. Up to $60 \%$ of patients can suffer from BCNS resulting from de novo mutations [10].

In overall, the disorder comprises five prevalent clinical manifestations: multiple nevoid BCCS, keratocystic odontogenic tumors (KOT), skeletal anomalies, lamellar calcification of falx cerebri and palms and/or plantar pits [11]. A detailed list of diverse clinical features in BCNS is displayed in Table 1 and comprises developmental anomalies together with tumors.

Developmental defects in BCNS include craniofacial anomaly, together with anomalies of the neurological system, axial skeleton, hands and feet. A characteristic coarse facial appearance includes frontal and temporal bossing, high and broad forehead, well-developed supraorbital ridges, hypertelorism, broad nasal root and wide nasal bridge, mandibular prognathism, internal strabismus and rotatory nystagmus $[12,13]$. The symptoms can be associated with hypoplastic maxilla and crossbite teeth relationship, high arched palate, cleft lip and palate, malocclusion and impacted teeth [12]. Macrocephaly is present at birth and is often associated with cerebral ventricular dilatation and empty sella [7]. Lamellar falx calcification is the most consistent radiological feature, which is usually present by the second decade and is asymptomatic [14]. Thoracic cage anomalies are congenital dysmorphic features present in the unchanged state from the fetal period in the form of bifid, splayed, or fused ribs, which are found incidentally on chest X-ray [11]. Anomalies of axial skeleton comprise spina bifida occulta, kyphoscoliosis, fusion defects and hemi vertebrae [12]. Palmar and/or plantar pits are superficial point depressions on palms and soles asymmetrically prevalent in BCNS in the late second decade. They are caused by a partial or complete absence of the horny layer in sharply defined areas ranging from 2 to $3 \mathrm{~mm}$ in diameter and 1 to $3 \mathrm{~mm}$ in depth [2].

Address for correspondence: Prof. Henryk Witmanowski MD, PhD, Department of Plastic, Reconstructive and Aesthetic Surgery, Medical College, Nicolaus Copernicus University, 9-11 M. Skłodowska-Curie St, 85-094 Bydgoszcz, phone: +48 52 585 4017, e- mail: hewit7@wp.pl Received: 21.06.2016, accepted: 2.08.2016. 
Table 1. Clinical picture of patients with BCNS

\begin{tabular}{|c|c|c|c|c|c|}
\hline \multirow{2}{*}{$\begin{array}{l}\text { Summarized clinical } \\
\text { manifestations }\end{array}$} & \multirow[t]{2}{*}{ Detailed clinical manifestations } & \multicolumn{3}{|c|}{ Reference } & \multirow[t]{2}{*}{ Our patien } \\
\hline & & [17] & [29] & [30] & \\
\hline \multirow[t]{7}{*}{ Tumors } & $\mathrm{BCC}$ & 75 & 90 & 37.8 & + \\
\hline & KOT & 75 & 90 & 86.3 & + \\
\hline & Epidermoid cysts of the skin & NA & $>50$ & NA & + \\
\hline & Ovarian fibroma & NA & 24 & 12.5 & \\
\hline & Medulloblastoma & NA & 5 & 3.3 & \\
\hline & Lymphomesenteric cysts & NA & $<5$ & NA & \\
\hline & Cardiac fibroma & NA & 2.5 & 2.1 & \\
\hline \multirow[t]{10}{*}{ Head } & Calcified falx cerebri & 92 & $>85$ & 79.4 & + \\
\hline & Coarse face & NA & 70 & 27.9 & + \\
\hline & Macrocephaly & 80 & 50 & 26.5 & + \\
\hline & Prognathism & 33 & NA & 25.2 & \\
\hline & Hypertelorism & 6 & NA & 68.8 & \\
\hline & Highly arched eyebrows & NA & NA & 44 & + \\
\hline & Frontoparietal bossing & 66 & NA & 47 & \\
\hline & Broad nasal bridge & 59 & NA & 58.4 & + \\
\hline & Eyeball abnormalities & NA & 7 & NA & \\
\hline & Cleft lip/palate & 4 & 6 & 9 & \\
\hline \multirow[t]{4}{*}{ Neurological system } & Hydrocephalus & NA & NA & 16.2 & + \\
\hline & Bridging of sella turcica & 26 & NA & 23.7 & \\
\hline & Mental retardation & NA & NA & 17.6 & \\
\hline & Epilepsy & NA & NA & 9 & \\
\hline \multirow[t]{5}{*}{ Axial skeleton } & Vertebral anomalies & 35 & 60 & 15.1 & + \\
\hline & Kyphoscoliosis & NA & $30-40$ & NA & \\
\hline & Rib anomalies & 45 & 60 & 36.4 & + \\
\hline & Sprengel deformity & 4 & NA & 2.7 & \\
\hline & Pectus deformity & 23 & NA & 6.1 & \\
\hline \multirow[t]{5}{*}{ Hands/feet } & Palmar and/or plantar pits & 80 & 65 & 69.2 & + \\
\hline & Syndactyly & NA & NA & 2.1 & \\
\hline & Polydactyly & NA & $<5$ & 1.5 & \\
\hline & Short $4^{\text {th }}$ metacarpals & 29 & NA & 10.5 & + \\
\hline & Flame shaped lucencies of hands/feet & NA & NA & 2.5 & \\
\hline Family history & & NA & NA & 48.4 & \\
\hline
\end{tabular}

NA- not applicable.

Tumors related to BCNS are BCC, KOT, epidermoid cysts of skin, ovarian fibroma, medulloblastoma, lymphomesenteric cysts, and cardiac fibroma in the descending frequency [15]. Nevoid BCCs are multiple and polymorphic. Naevus emphasizes their early onset with BCCS developed in about $50 \%$ of patients aged $>20$ years and in up to $90 \%$ of patients by the age of $40[16,17]$. Their appearance and clinical characteristics are variable, from less aggressive brownish flesh-colored basal cell nevi to very aggressive forms present usually in sun-exposed areas [18]. Jaw cysts, KOTs, are benign cystic lesions containing a clear fluid with a slowly progressive nature, local invasion tendency affecting the teeth, and a high recurrence rate of $60 \%$ due to thin lining of the fibrous 
Table 2. Diagnostic criteria for BCNS in our patient (based on Kimonis et al. [15])

\begin{tabular}{lccc}
\hline Major criteria & Our patient & Minor criteria & Our patient \\
\hline $\begin{array}{l}\text { Multiple }(>2) \text { BCCs or } 1 \mathrm{BCC} \text { in } \\
\text { a patient aged }<20 \text { years }\end{array}$ & + & $\begin{array}{c}\text { Macrocephaly determined after adjustment for height: OFC } \\
\text { (occipitofrontal circumference) }>97^{\text {th }} \text { percentile }\end{array}$ & + \\
\hline $\begin{array}{l}\text { Mandibular or maxillary KOT } \\
\text { confirmed on histology }\end{array}$ & + & $\begin{array}{c}\text { Congenital malformations: cleft lip/palate, frontal bossing, } \\
\text { coarse face, moderate or severe hypertelorism }\end{array}$ & + \\
\hline $\begin{array}{l}\text { Pitted depressions on hands or feet } \\
\text { (palmar or plantar pits) }(\geq 3 \text { lesions) }\end{array}$ & + & $\begin{array}{c}\text { Skeletal abnormalities: Sprengel deformity, pectus deformity, } \\
\text { finger syndactyly }\end{array}$ \\
\hline $\begin{array}{l}\text { Ectopic calcification: lamellar } \\
\text { calcification of the falx cerebri }\end{array}$ & + & $\begin{array}{c}\text { Radiological abnormalities: bridging of the sella turcica, } \\
\text { vertebral anomalies (hemivertebrae, fusion or elongation of } \\
\text { the vertebral bodies), deformities of hands and feet }\end{array}$ \\
\hline Bifid, fused or markedly expanded ribs & + & Ovarian fibroma \\
\hline First-degree relative with BCNS & & Medulloblastoma \\
\hline
\end{tabular}

capsule and presence of satellite cysts [12]. The tumors, present in $75 \%$ of patients with BCNS, are found as the first features of the syndrome either incidentally on radiographic examination of jaws often as bilateral lesions or treated due to a secondary infection or displacement of developing teeth $[19,20]$. The other tumors occurring with a low prevalence in BCNS are medulloblastoma, cardiac fibroma and ovarian fibroma [7]. The age predilection for tumors in BCNS is in the first to third decade of life, with the onset age of cardiac fibroma at 0-1 months, medulloblastoma at $2-3$ years, BCC at 3-53 years, KOT at 6-12 years and ovarian fibroma at 16-45 years [12].

Clinical and radiological diagnostic criteria were proposed by Evans et al. and modified by Kimonis et al. (Table 2) $[15,16]$. The BCNS is diagnosed based on meeting either two major criteria, or one major criterion and two minor ones [4].

The aim of our work is to present a case of Gorlin-Goltz syndrome, review its genetic predisposition, clinical picture and treatment.

A 39-year-old male patient from the Central-Eastern Europe was referred to the Plastic Surgery Clinic with multiple BCCs (Figure 1). On general physical examination, the patient was well built and nourished. His coarse facial appearance comprised macrocephaly, highly arched eyebrows and a broad nasal bridge (Table 1 ).

The first BCC appeared when he was 17 years old and appeared gradually on various parts of his body, starting gradually from the abdominal wall, posterior trunk and face. He was not exposed to excessive environmental risk factors for skin cancer. In the past, the BCC lesions were treated with various modalities over years, including laser therapy, radiotherapy and surgery, and were biopsy proven. In our clinic, diagnosis of BCC was confirmed by histopathology following the surgical excision (Figure 2).

The patient was evaluated systemically for other anomalies of the skeletal, cardiovascular, central nervous and integumentary systems. He presented with abnormal dentition associated with unerupted teeth. In the past, he was surgically treated for KOT, which was histologically proven (Figure 2). Computed tomography scan of the head revealed lamellar calcification of the falx cerebri (Figure 3 B). He was diagnosed for hydrocephalus with skull $X$-ray when he was aged 2 years. Electroencephalogram, ECG, ECHO and abdominal US studies were within their normal limits. The patient had a biopsyproven epidermoid cyst in his left lumbar region. There were multiple brownish palmar pits on both his hands (Figure 4). The patient's other medical and family history was noncontributory. The patient was single and did not have any children.

The clinical, radiological and histopathological findings met major and minor criteria for diagnosis of the BCNS (Gorlin-Goltz syndrome) (Table 2).

The diagnostic process in patients suspected of BCNS includes physical examination and imaging studies. The physical examination must include oral exploration, cephalic diameter, craniofacial morphology, skin exploration, and evaluation of the palms and soles [4]. Skull $X$-rays, orthopantogram, chest $X$-ray, and spinal $X$-ray are required as complementary tests. Ultrasound examinations are used to diagnose cardiac and ovarian fibromas [1]. Brain magnetic resonance imaging may prove to be important for the detection of meningiomas or medulloblastomas in patients with BCNS in the first years of life [4]. The diagnosis of BCNS can be confirmed by the detection of a mutation of the PTCH gene although PTCH mutations have also been found in other sporadic malignancies, such as medulloblastomas, skin trichoepitheliomas, esophageal squamous cell carcinomas, squamous cell carcinomas, breast cancer, colon cancer, as well as in KOT [21].

The therapy of patients with BCNS requires a multidisciplinary approach. For the limited BCCs, various forms of treatment have been described, and the firstline treatment is usually surgical excision by standard or micro excisional/Mohs techniques, especially for nodular or aggressive BCCS.

Minimally invasive treatment modalities for low risk superficial BCCs include electrodessication and curet- 

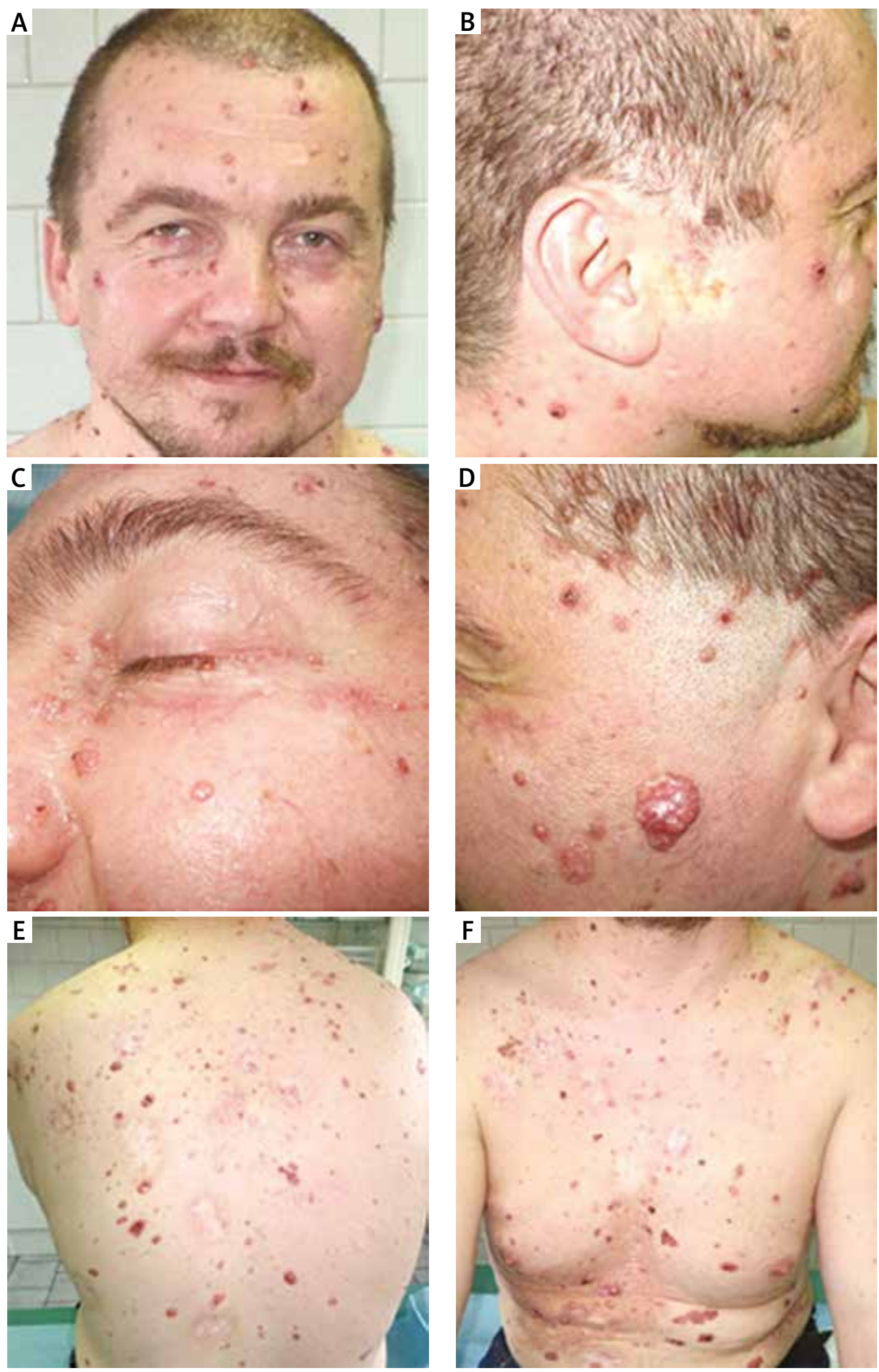

Figure 1. Photograph of the patient showing multiple BCCs of the face and trunk 

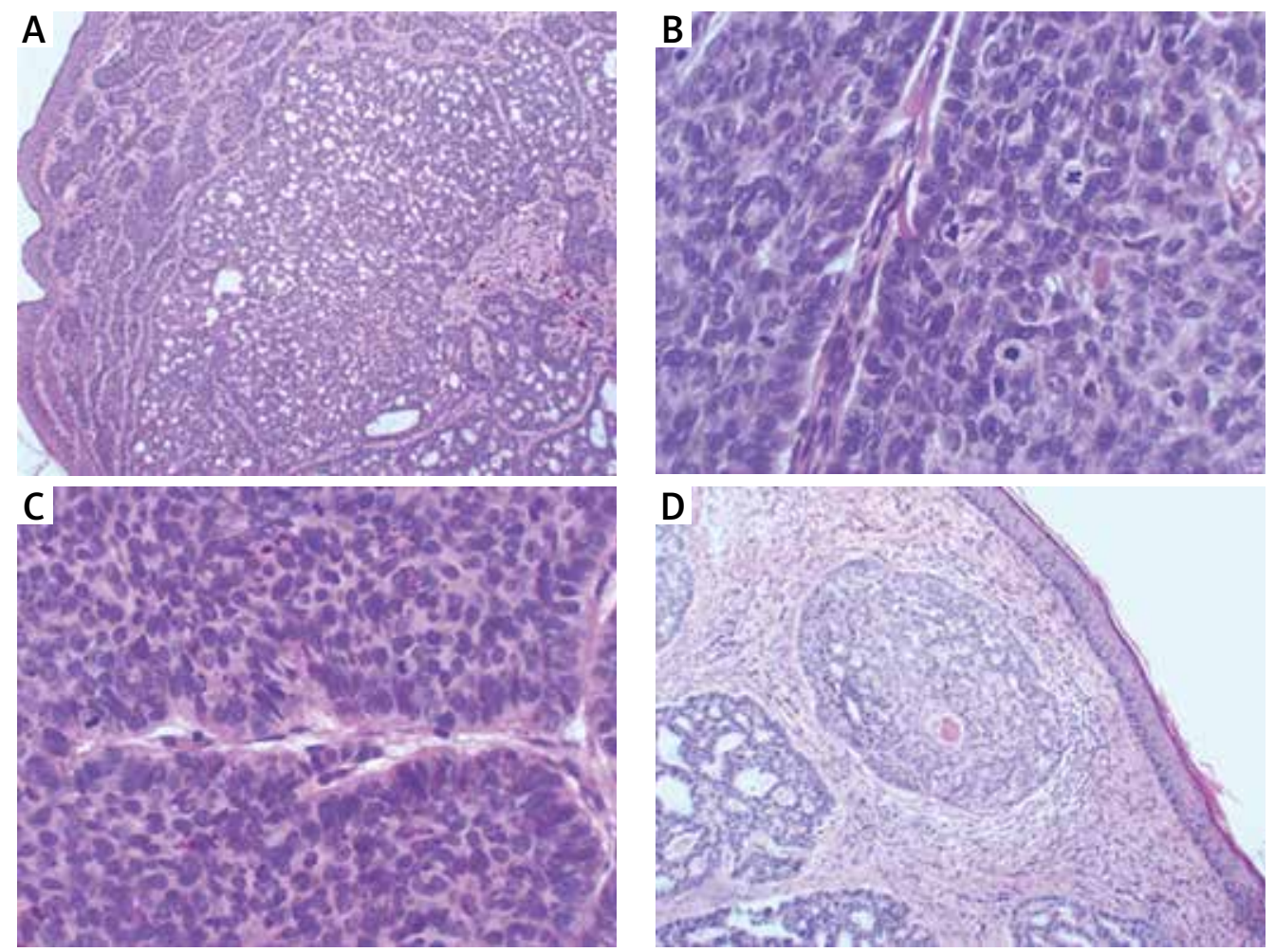

Figure 2. Histological sections of 4 BCCs: A - 10x magnification, B - high mitotic activity at 40x magnification, C - palisades on the periphery and the figures of cell division at $40 \times$ magnification, $D-$ focal acanthosis at 10x magnification

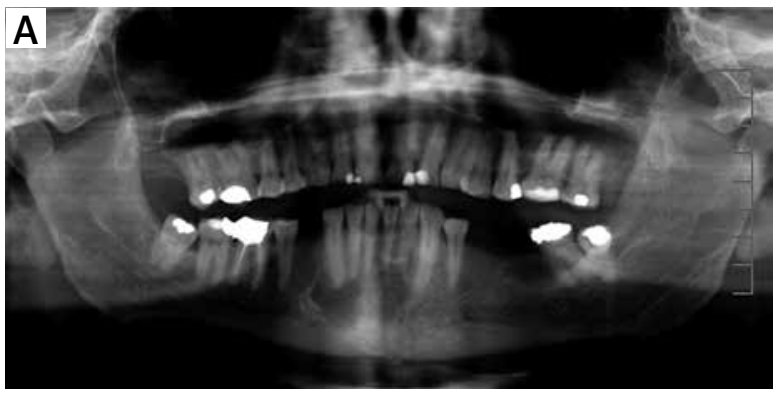

Figure 3. Radiological findings associated with Gorlin syndrome: $\mathbf{A}$ - orthopantogram showing multiple jaw cysts (unilocular well-defined radiolucent lesions with sclerotic borders) in relation to impacted and unerupted teeth odontogenic keratocysts, B - CT scan of the head showing calcification of the falx cerebri

tage, cryotherapy, carbon dioxide laser ablation, photodynamic therapy (PDT) or electrochemotherapy. Photodynamic therapy is considered as an effective and safe therapy for superficial BCCs and in nodular BCCs $<2 \mathrm{~mm}$ in thickness, by use of a photosensitizing dye given intravenously or topically [3]. However, the procedure is painful and can induce erythema, scabbing and blister

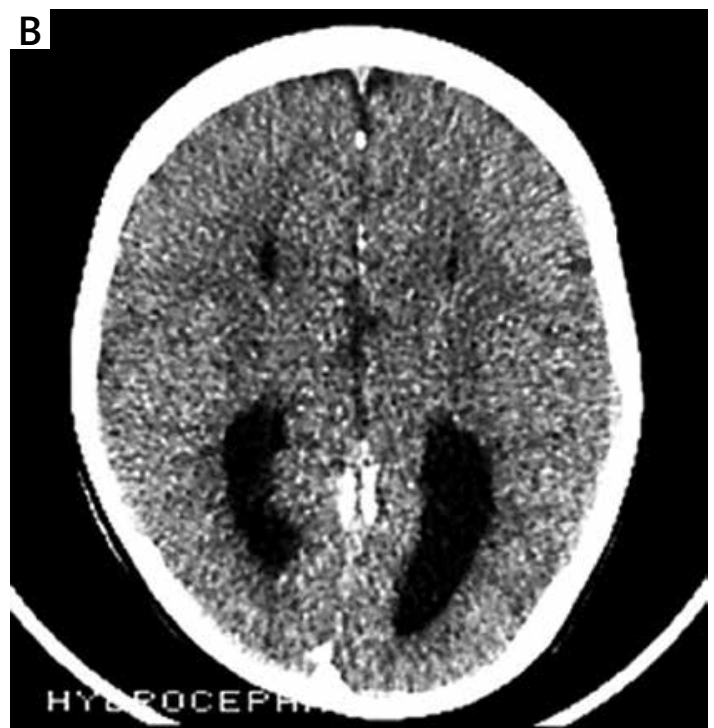

formation. Pharmacological topical approaches to treat superficial BCCs comprise creams with $0.1 \%$ tretinoin, $5 \%$ fluorouracil or 5\% imiquimod [22]. Topical approaches require a long duration which may lead to poor patient compliance. Immunomodulators, such as imiquimod, can lead to local inflammation and need to be applied on a limited area of the affected skin [23]. Systemic 

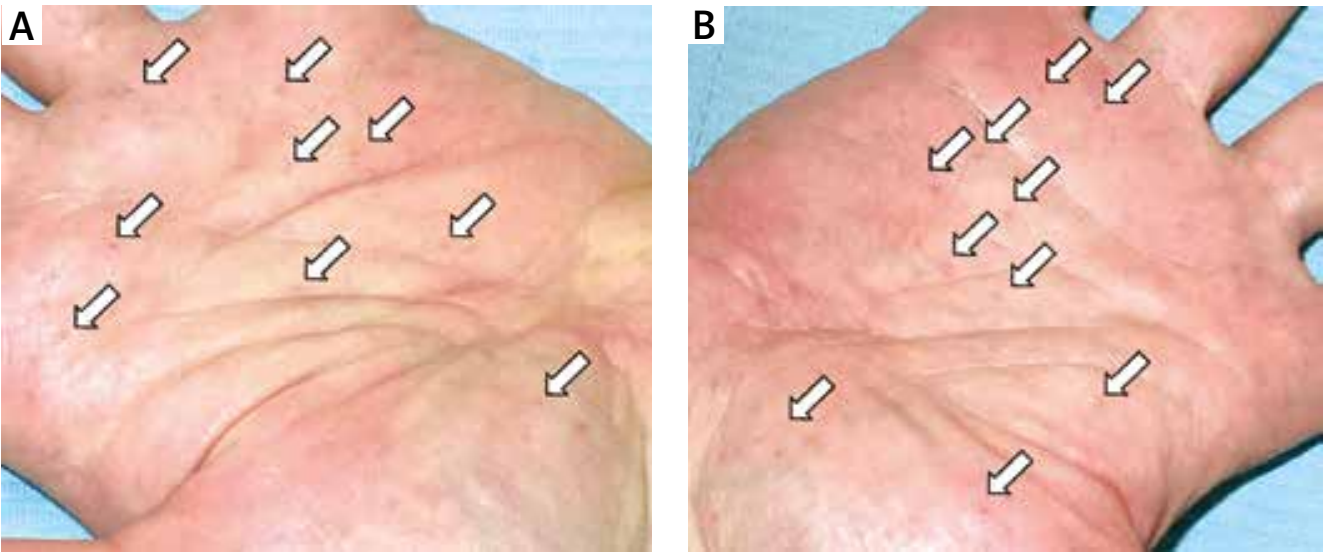

Figure 4. Multiple palmar pits on both hands

treatment includes oral retinoids (isotretinoin at doses of $0.5-1 \mathrm{mg} / \mathrm{kg} /$ day) or oral etretinate $(0.5-1 \mathrm{mg} / \mathrm{kg} /$ day $)$ in lesions of less than $1 \mathrm{~cm}$ as well as capecitabine (a systemic prodrug of fluorouracil) as palliative treatment [24, 25]. Oral retinoids inhibit the development of new BCCS [24]. On contrary, radiation therapy can have possible deleterious effects on the local skin cancer recurrence risk or new tumor growth [13].

KOT is treated with surgical excision in the form of enucleation, curettage, marginal osteotomy, or segmental osteotomy [12]. Alternative approaches are cryotherapy or application of Carnoy's solution [26]. Recurrence after surgery is reported at a rate of $6-60 \%$ and is attributable to incomplete resection, dental lamina remaining within the maxillas, or the presence of satellite cysts [4]. Therefore, close dental follow-up is obligatory [2].

Future treatment options in BCNS patients include PTCH1- or SMO-specific targeted drugs which prevent the expression of tumor mediating genes within the hedgehog pathway. Vismodegib and sonidegib are hedgehog pathway inhibitors approved for metastatic or recurrent BCC or patients who are not surgical or radiation candidates [10]. Vismodegib actually reduces the BCC tumor burden and blocks growth of new BCC in patients with Gorlin syndrome [27]. The future treatment alternatives are modulating therapies of hedgehog signaling, which include Gli1 inhibitor, PI3K-mTOR inhibitor, and PKC inhibitor [28].

In summary, numerous symptoms of the BCNS genodermatosis can be successfully treated systemically or locally, usually with surgical interventions or other therapeutic alterations. Patients with BCNS require screening at birth for cardiac, palatal or neural defects, for medulloblastoma twice yearly in the early childhood, for KOT from late childhood and for BCCs throughout life with at least two dermatological examinations on a yearly basis. Children should be evaluated for hydrocephalus in case of a rapid increase in the occipitofrontal circumference. A yearly panoramic X-ray study of jaws for KOT screen- ing is recommended in children older than 8 years. In turn, radiotherapy and frequent computer tomography are relatively contraindicated. Sun exposure should be limited. Patients with BCNS have a very good prognosis with normal life expectancy, except from rare cases of very aggressive multiple BCCs or medulloblastoma [4]. Patients and their children should be counselled about the hereditary nature of BCNS, and they should be offered genetic testing for familiar cancer syndrome [29].

\section{Conflict of interest}

The authors declare no conflict of interest.

\section{References}

1. High A, Zedan W. Basal cell nevus syndrome. Cur Opin Oncol 2005; 17: 160-6.

2. Daneswari M, Reddy MS. Genetic mutations in Gorlin-Goltz syndrome. Indian J Hum Genet 2013; 19: 369-72.

3. Basset-Seguin N, Bissonnette R, Girard C, Haedersdal M, et al. Consensus recommendations for the treatment of basal cell carcinomas in Gorlin syndrome with topical methylaminolaevulinate-photodynamic therapy. J Eur Acad Dermatol Venereol 2014; 28: 626-32.

4. García de Marcos JA, Dean-Ferrer A, Arroyo Rodríguez S, et al. Basal cell nevus syndrome: clinical and genetic diagnosis. Oral Maxillofac Surg 2009; 13: 225-30.

5. Shahmoradi Z, Andalib F, Siadat AH. Naevoid basal cell carcinoma syndrome. Indian I Dermatol Venereol Leprol 2010; 76: 71-3.

6. Bholah Z, Smith MJ, Byers HJ, Miles EK, et al. Intronic splicing mutations in PTCH1 cause Gorlin syndrome. Fam Cancer 2014; 13: 477-80.

7. Fujii K, Miyashita T. Gorlin syndrome (nevoid basal cell carcinoma syndrome): update and literature review. Pediatr Int 2014; 56: 667-74.

8. Singh AK, Lopez-Araujo A, Katabathina VS. Gorlin syndrome. J Pediatr 2014; 164: 1501-e1.

9. Athar M, Li C, Kim AL, et al. Sonic hedgehog signaling in basal cell nevus syndrome. Cancer Res 2014; 74: 4967-75. 
10. Griner D, Sutphin D, Sargent LA. Surgical management of Gorlin syndrome: a 4-decade experience using local excision technique. Ann Plast Surg 2015; 74: 467-70.

11. Mufaddel A, Alsabousi M, Salih B, et al. A case of GorlinGoltz syndrome presented with psychiatric features. Behav Neurol 2014; 2014: 830874.

12. Anehosur V. Gorlin's syndrome - report of a case and management of cystic lesions. J Maxillofac Oral Surg 2009; 8: 184-7.

13. Mohan RP, Verma S, Agarwal N, Singh U. Gorlin-Goltz syndrome: a rare case report. BMJ Case Rep 2013; 2013: Pii:bcr2013010409.

14. Mitchell G, Farndon PA, Brayden P, et al. Genetic predisposition to cancer: the consequences of a delayed diagnosis of Gorlin syndrome. Clin Oncol (R Coll Radiol) 2005; 17: 650-4.

15. Kimonis VE, Goldstein AM, Pastakia B, et al. Clinical manifestations in 105 persons with nevoid basal cell carcinoma syndrome. Am J Med Genet 1997; 69: 299-308.

16. Evans DG, Ladusans EJ, Rimmer S, et al. Complications of the naevoid basal cell carcinoma syndrome: results of a population based study. J Med Genet 1993; 30: 460-4.

17. Endo M, Fujii K, Sugita K, et al. Nationwide survey of nevoid basal cell carcinoma syndrome in Japan revealing the low incidence of basal cell carcinoma. Am J Med Genet 2012; 158A: 351-7.

18. Díaz-Fernández JM, Infante-Cossío P, Belmonte-Caro R, et al. Basal cell nevus syndrome. Presentation of six cases and literature review. Med Oral Patol Oral Cir Bucal 2005; 10: E57-66.

19. Blanchard SB. Odontogenic keratocyst: review of the literature and report of a case. J Periodontol 1997; 68: 306-11.

20. Lo Muzio L, Pastorino L, Levanat S, et al. Clinical utility gene card for: Gorlin syndrome-update 2013. Eur J Hum Genet 2013; 21: doi: 10.1038/ejhg.2012.299.

21. Veenstra-Knol HE, Scheewe JH, van der Vlist GJ, et al. Early recognition of basal cell naevus syndrome. Eur J Pediatr 2005; 164: 126-30.

22. Love WE, Bernhard JD, Bordeaux JS. Topical imiquimod or fluorouracil therapy for basal and squamous cell carcinoma: a systematic review. Arch Dermatol 2009; 145: 1431-8.

23. Stokfleth E, Meyer T, Benninghoff B, et al. A randomized, double-blind, vehicle-controlled study to assess $5 \%$ imiquimod cream for the treatment of multiple actinic keratoses. Arch Dermatol 2002; 138: 1498-502.

24. Agrawal SN, Daware PP, Deshmukh YR, Jane S. Gorlins's syndrome: atypical case report. Our Dermatol Online 2014; 5 : 378-80.

25. Beach DF, Somer R. Novel approach to Gorlin syndrome: a patient treated with oral capecitabine. J Clin Oncol 2011; 29: e397-401.

26. Ortega-García de Amezaga A, García-Arregui O, Zepeda-Nuńo S, et al. Gorlin-Goltz syndrome: clinicopathologic aspects. Med Oral Patol Oral Cir Bucal 2008; 13: e338-43.

27. Yauch RL, Dijkgraaf GJ, Alicke B, et al. Smoothened mutation confers resistance to a Hedgehog pathway inhibitor in medulloblastoma. Science 2009; 326: 572-4.

28. Amakye D, Jagani Z, Dorsch M. Unraveling the therapeutic potential of the Hedgehog pathway in cancer. Nat Med 2013; 19: 1410-22.

29. Farndon PA. The Gorlin syndrome. In: Genetic Predisposition of Cancer. $2^{\text {nd }}$ edn. Eles RA, Easton DF, Ponder BAJ, Eng C (eds). Arnolds, London 2004; 193-213.
30. Shanley S, Ratcliffe J, Hockey A, et al. Nevoid basal cell carcinoma syndrome: Review of 118 affected individuals. Am J Med Genet 1994; 50: 282-90. 